\title{
Valve-in-valve TAVR using the SAPIEN 3 transcatheter heart valve: still plagued by patient-prosthesis mismatch
}

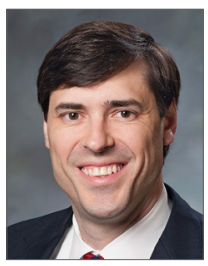

\author{
John T. Saxon ${ }^{1,2}$, MD; David J. Cohen ${ }^{1,2}$, MD, MSc; Ted Feldman ${ }^{3 *}$, MD, FESC, FACC, MSCAI
}

1. Saint Luke’s Mid America Heart Institute, Kansas City, MO, USA; 2. University of Missouri, Kansas City School of Medicine, Kansas City, MO, USA; 3. NorthShore University Health System, Evanston, IL, USA

Valve-in-valve (VinV) transcatheter aortic valve replacement (TAVR) has become a well-established therapy for patients with failed surgical bioprosthetic valves (BPV) who are at high risk for reoperation ${ }^{1}$. In the largest series to date, VinV TAVR demonstrated a one-year survival rate of $83.2 \%$, which was similar to that of patients undergoing native aortic stenosis (AS) TAVR in high-risk populations ${ }^{2,3}$. Of note, in that series, most patients $(53.4 \%)$ were treated with a second-generation balloon-expandable transcatheter heart valve (THV), namely the SAPIEN XT THV (Edwards Lifesciences, Irvine, CA, USA).

Over the decade since its introduction for the treatment of native AS, iterative modifications to THV design and functionality as well as advances in imaging and procedural technique have led to a dramatic improvement in both safety and patient outcomes over the original procedures ${ }^{4}$. In particular, the secondgeneration SAPIEN XT valve has now been largely replaced by the SAPIEN 3 valve (Edwards Lifesciences), which has several new features specifically designed for use in native AS TAVR. These include a fabric cuff to reduce paravalvular leak (PVL), a longer stent frame to simplify deployment positioning within the native aortic annulus, and a smaller crimped profile (18-21 Fr outer diameter) that allows introduction into smaller (14-16 Fr) expandable sheaths. The performance of the SAPIEN 3 in native AS has been promising ${ }^{4}$. What is not known to date, however, is whether the SAPIEN 3 THV would perform as well as or better than the SAPIEN XT in VinV TAVR.

In this issue of EuroIntervention, Seiffert and colleagues have used an expanded data set from the VIVID registry to answer that very question ${ }^{5}$.

\section{Article, see page 397}

They report the procedural and intermediate-term outcomes of 514 patients who underwent VinV TAVR using SAPIEN XT $(n=370)$ and SAPIEN $3(n=144)$ THVs. Because of the retrospective, observational nature of the VIVID registry, the authors made an effort to minimise confounding between the two groups by using inverse probability of treatment (IPT) weighting according to the propensity to receive one or other valve. After applying IPT weighting, the resulting groups had roughly similar baseline characteristics and predicted surgical risk (STS PROM 8.6 $\pm 6.6 \%$ for the SAPIEN 3, 7.3 $\pm 5 \%$ for the SAPIEN XT), but some residual baseline differences between the two groups remained. For example, there was a larger proportion of patients with a small surgical bioprosthesis $(\leq 19 \mathrm{mmHg})$ in the XT group than in the SAPIEN 3 group.

Not surprisingly, the SAPIEN 3 valve performed well. The results of SAPIEN 3 as compared with SAPIEN XT VinV procedures mirror those in native AS TAVR. Rates of permanent pacemaker placement were slightly higher with SAPIEN 3 than 
XT $(6.0 \%$ vs. $2.5 \%, \mathrm{p}=0.071)$, while the rate of residual paravalvular regurgitation was lower (none $85.4 \%$ vs. $69.6 \%$; mild $12.5 \%$ vs. $25.2 \%$; moderate or greater $2.1 \%$ vs. $5.2 \%$; $<<0.001$ ). In addition, all-cause mortality at 30 days trended in favour of SAPIEN $3(0.6 \%)$ versus XT $(3.5 \%, \mathrm{p}=0.077)$, although this result is unlikely to be related to the haemodynamic performance of the THV since there was no difference in residual mean transvalvular gradient between the two devices (SAPIEN 3, $16.9 \mathrm{mmHg}$; $\mathrm{XT}, 17.4 \mathrm{mmHg}, \mathrm{p}=0.536$ ). Most likely, the observed difference in early mortality reflects the substantial increase in the use of transfemoral access afforded by the SAPIEN 3 THV as compared with XT $(88.2 \%$ vs. $58.5 \%, \mathrm{p}<0.001)$, with corresponding reductions in the incidence of VARC major/life-threatening bleeding $(1.9 \%$ vs. $6.0 \% ; \mathrm{p}=0.065)$. It is also possible that the difference in shortterm mortality could be related to greater operator experience in the SAPIEN 3 group, since these implants occurred at a later time than the majority of the SAPIEN XT implants.

The results of this study are important for contemporary clinical practice, and they add to the growing knowledge in the discipline of VinV TAVR. Nonetheless, one should be somewhat circumspect about the strength of conclusions that can be drawn from these observational data. As noted previously, the method of risk adjustment using IPT weighting resulted in roughly similar but still distinct groups with respect to observed covariates. Furthermore, as with any observational study, there is also the very real possibility that some of the results can also be explained by unmeasured confounding. What is clear, however, is that, notwithstanding the important limitations noted above, the SAPIEN 3 THV performed at least as well as, and possibly better than, the second-generation SAPIEN XT THV. Based on this study, operators should have no hesitation in transitioning from the SAPIEN XT to the SAPIEN 3 valve during VinV procedures if a balloon-expandable THV is chosen.

Perhaps the most important message from this study is that the SAPIEN 3 device does not overcome the most important limitation of balloon-expandable THVs for VinV TAVR - patientprosthesis mismatch (PPM). As in previous studies, a substantial proportion of patients had a residual mean transvalvular gradient of $>20 \mathrm{mmHg}$ with either the SAPIEN 3 or SAPIEN and XT THVs $(38.3 \%$ vs. $35.7 \%, \mathrm{p}=0.627)$. In order to gain a deeper understanding of this issue, the authors examined the relationship between implant depth and residual gradient in a subset of patients who underwent SAPIEN 3 implantation. The results of this careful analysis were sobering: even in the group with an optimal implant depth (defined as $<20 \%$ of the stent frame extending below the surgical BPV annulus), a substantial proportion had residual gradients $\geq 20 \mathrm{mmHg}$ after VinV TAVR ${ }^{5}$. These findings demonstrate that, even though a high implant depth has been suggested as a method to address PPM, this approach does not fully address this limitation imposed by intra-annular $\mathrm{THVs}^{6,7}$.

The relationship between PPM and increased mortality is well established for both surgical AVR and VinV TAVR. Using data from the VIVID registry, Dvir and colleagues noted a strong association between the size of the surgical BPV and one-year mortality (higher with smaller valves) ${ }^{1}$. Although presence of severe PPM was not directly associated with increased mortality in the original VIVID data, the presence of a residual gradient $>20 \mathrm{mmHg}$ was a strong predictor of mortality in the PARTNER 2 Valve-in-Valve Registry, which used SAPIEN XT THVs in highrisk patients ${ }^{8}$. Finally, Pibarot and colleagues have demonstrated a clear association between the presence of pre-existing PPM within the surgical BPV and increased mortality following VinV TAVR $^{9}$.

Recently, a novel technique, bioprosthetic valve fracture (BVF), has been developed wherein the surgical BPV ring is fractured by means of high-pressure balloon inflation using a non-compliant valvuloplasty balloon in order to dilate the BPV and permit further expansion of the $\mathrm{THV}^{10-12}$. This technique has been shown to improve the haemodynamic results of VinV TAVR in patients at risk for $\mathrm{PPM}^{13-17}$. In the largest series to date, the mean transvalvular gradient was reduced from $41.9 \mathrm{mmHg}$ pre-procedure to $20.5 \mathrm{mmHg}$ after VinV TAVR, and further reduced from 20.5 $\mathrm{mmHg}$ to $6.7 \mathrm{mmHg}$ following BVF ( $<<0.001$ for both comparisons). These mean gradients correspond to calculated effective orifice areas of $0.6 \mathrm{~cm}^{2}, 1.0 \mathrm{~cm}^{2}$, and $1.7 \mathrm{~cm}^{2}$, respectively. As such, the benefit of BVF to improve the immediate procedural results of VinV TAVR is clearly evident.

Bench testing of clinically available BPV has also supported this concept, as most commercially available BPV can be fractured with a high-pressure balloon inflation using a non-compliant, Kevlar-wrapped valvuloplasty balloon ${ }^{13,16}$. Nonetheless, BVF may carry an increased risk in addition to that of stand-alone VinV $\mathrm{TAVR}^{17}$, such that procedural complications and best practices will need to be further characterised as this technique is offered to a wider population of patients. Longer-term follow-up of patients undergoing BVF will also be necessary to understand whether the initial haemodynamic benefits are sustained and whether there are any adverse consequences with respect to valve durability. Finally, the advent of surgical BPV with intentionally expandable rings (e.g., the INSPIRIS RESILIA BPV; Edwards Lifesciences) may also offer a solution if VinV procedures are later required. Whether future iterations of surgical BPV will have features to prevent PPM, and whether these valves will have wide adoption by cardiothoracic surgeons, remains to be seen.

In any event, it is clear from the continued work of the VIVID registry, the advent of BVF to facilitate VinV TAVR, and the introduction of expandable surgical valves, that operators and industry understand the problem of PPM and are making strides to address this challenge. Undoubtedly, these advances will lead to the continued use of VinV TAVR as an effective therapy for patients now and in the future.

\section{Conflict of interest statement}

D. Cohen reports receiving research grant support from Edwards Lifesciences, Medtronic, Abbott Vascular and Boston Scientific, and consulting income from Edwards Lifesciences and Medtronic. 
T. Feldman reports receiving research grant support from Abbott, Edwards Lifesciences and Boston Scientific, and honoraria from Edwards Lifesciences and Boston Scientific. The other author has no conflicts of interest to declare.

\section{References}

1. Dvir D, Webb JG, Bleiziffer S, Pasic M, Waksman R, Kodali S, Barbanti M, Latib A, Schaefer U, Rodés-Cabau J, Treede H, Piazza N, Hildick-Smith D, Himbert D, Walther T, Hengstenberg C, Nissen H, Bekeredjian R, Presbitero P, Ferrari E, Segev A, de Weger A, Windecker S, Moat NE, Napodano M, Wilbring M, Cerillo AG, Brecker S, Tchetche D, Lefèvre T, De Marco F, Fiorina C, Petronio AS, Teles RC, Testa L, Laborde JC, Leon MB, Kornowski R; Valve-in-Valve International Data Registry Investigators. Transcatheter aortic valve implantation in failed bioprosthetic surgical valves. JAMA. 2014;312:162-70.

2. Smith CR, Leon MB, Mack MJ, Miller DC, Moses JW, Svensson LG, Tuzcu EM, Webb JG, Fontana GP, Makkar RR, Williams M, Dewey T, Kapadia S, Babaliaros V, Thourani VH, Corso P, Pichard AD, Bavaria JE, Herrmann HC, Akin JJ, Anderson WN, Wang D, Pocock SJ; PARTNER Trial Investigators. Transcatheter versus surgical aortic-valve replacement in high-risk patients. N Engl J Med. 2011;364:2187-98.

3. Adams DH, Popma JJ, Reardon MJ. Transcatheter aorticvalve replacement with a self-expanding prosthesis. $N$ Engl J Med. 2014;371:967-8.

4. Herrmann HC, Thourani VH, Kodali SK, Makkar RR, Szeto WY, Anwaruddin S, Desai N, Lim S, Malaisrie SC, Kereiakes DJ, Ramee S, Greason KL, Kapadia S, Babaliaros V, Hahn RT, Pibarot P, Weissman NJ, Leipsic J, Whisenant BK, Webb JG, Mack MJ, Leon MB; PARTNER Investigators. One-Year Clinical Outcomes With SAPIEN 3 Transcatheter Aortic Valve Replacement in High-Risk and Inoperable Patients With Severe Aortic Stenosis. Circulation. 2016;134:130-40.

5. Seiffert M, Treede H, Schofer J, Linke A, Woehrle J, Baumbach H, Mehilli J, Bapat V, Simonato M, Walther T, Kullmer M, Boekstegers P, Ensminger S, Kurz T, Eltchaninoff $\mathrm{H}$, Rastan A, Werner N, de Weger A, Frerker C, Lauer B, Muller O, Whisenant B, Thukkani A, Weisz G, Dvir D. Matched comparison of next- and early-generation balloon-expandable transcatheter heart valve implantations in failed surgical aortic bioprostheses. EuroIntervention. 2018;14:e397-404.

6. Azadani AN, Reardon M, Simonato M, Aldea G, Nickenig G, Kornowski R, Dvir D. Effect of transcatheter aortic valve size and position on valve-in-valve hemodynamics: An in vitro study. J Thorac Cardiovasc Surg. 2017;153:1303-15.e1.

7. Simonato M, Azadani AN, Webb J, Leipsic J, Kornowski R, Vahanian A, Wood D, Piazza N, Kodali S, Ye J, Whisenant B, Gaia D, Aziz M, Pasala T, Mehilli J, Wijeysundera HC, Tchetche D, Moat N, Teles R, Petronio AS, Hildick-Smith D, Landes U, Windecker S, Arbel Y, Mendiz O, Makkar R, Tseng E, Dvir D. In vitro evaluation of implantation depth in valve-in-valve using different transcatheter heart valves. EuroIntervention. 2016;12: 909-17.

8. Webb JG, Mack MJ, White JM, Dvir D, Blanke P, Herrmann HC, Leipsic J, Kodali SK, Makkar R, Miller DC, Pibarot P, Pichard A, Satler LF, Svensson L, Alu MC, Suri RM, Leon MB. Transcatheter Aortic Valve Implantation Within Degenerated Aortic Surgical Bioprostheses: PARTNER 2 Valve-inValve Registry. J Am Coll Cardiol. 2017;69:2253-62.

9. Pibarot P, Simonato M, Barbanti M, Linke A, Kornowski R, Rudolph T, Spence M, Moat N, Aldea G, Mennuni M, Iadanza A, Amrane H, Gaia D, Kim WK, Napodano M, Baumbach H, Finkelstein A, Kobayashi J, Brecker S, Don C, Cerillo A, Unbehaun A, Attias D, Nejjari M, Jones N, Fiorina C, Tchetche D, Philippart R, Spargias K, Hernandez JM, Latib A, Dvir D. Impact of Pre-Existing Prosthesis-Patient Mismatch on Survival Following Aortic Valve-in-Valve Procedures. JACC Cardiovasc Interv. 2018;11:133-41.

10. Nielsen-Kudsk JE, Christiansen EH, Terkelsen CJ, Norgaard BL, Jensen KT, Krusell LR, Tang M, Terp K, Klaaborg KE, Andersen HR. Fracturing the Ring of Small Mitroflow Bioprostheses by High-Pressure Balloon Predilatation in Transcatheter Aortic Valve-in-Valve Implantation. Circ Cardiovasc Interv. 2015;8: e002667.

11. Brown SC, Cools B, Gewillig M. Cracking a tricuspid perimount bioprosthesis to optimize a second transcatheter sapien valvein-valve placement. Catheter Cardiovasc Interv. 2016;88:456-9.

12. Tanase D, Grohmann J, Schubert S, Uhlemann F, Eicken A, Ewert P. Cracking the ring of Edwards Perimount bioprosthesis with ultrahigh pressure balloons prior to transcatheter valve in valve implantation. Int J Cardiol. 2014;176:1048-9.

13. Allen KB, Chhatriwalla AK, Cohen DJ, Saxon JT, Aggarwal S, Hart A, Baron S, Davis JR, Pak AF, Dvir D, Borkon AM. Bioprosthetic Valve Fracture to Facilitate Transcatheter Valve-inValve Implantation. Ann Thorac Surg. 2017;104:1501-8.

14. Chhatriwalla AK, Allen KB, Saxon JT, Cohen DJ, Aggarwal S, Hart AJ, Baron SJ, Dvir D, Borkon AM. Bioprosthetic Valve Fracture Improves the Hemodynamic Results of Valve-in-Valve Transcatheter Aortic Valve Replacement. Circ Cardiovasc Interv. 2017 Jul;10(7).

15. Nielsen-Kudsk JE, Andersen A, Therkelsen CJ, Christensen EH, Jensen KT, Krusell LR, Tang M, Terp KA, Klaaborg KE, Greisen JR, Norgaard BL, Andersen HR. Highpressure balloon fracturing of small dysfunctional Mitroflow bioprostheses facilitates transcatheter aortic valve-in-valve implantation. EuroIntervention. 2017;13:e1020-5.

16. Johansen P, Engholt H, Tang M, Nybo RF, Rasmussen PD, Nielsen-Kudsk JE. Fracturing mechanics before valve-in-valve therapy of small aortic bioprosthetic heart valves. EuroIntervention. 2017;13:e1026-31.

17. Saxon JT, Allen KB, Cohen DJ, Chhatriwalla AK. Bioprosthetic Valve Fracture During Valve-in-valve TAVR: Bench to Bedside. Interv Cardiol. 2018;13:20-6. 